\title{
A PALAVRA ECOPOÉTICA DE CECÍLIA MEIRELES ${ }^{1}$
}

\section{THE ECOPOETIC WORD OF CECÍLIA MEIRELES}

\section{Anélia Montechiari Pietrani²}

RESUMO: Este ensaio pretende refletir sobre as relações entre poesia, educação e compromisso social de Cecília Meireles, percorrendo a visão ecopoética na leitura de sua obra. Objetiva-se, com isso, destacar sua ética pacifista tanto como educadora quanto como poeta, tomando como ponto principal de análise comparativa os poemas "Lamento do oficial por seu cavalo morto", do livro Mar absoluto (1945), e "Elegia a uma pequena borboleta", de Retrato natural (1949).

Palavras-chave: Cecília Meireles. Ecopoesia. Lírica social. Pacifismo.

ABSTRACT: This paper intends to reflect on the relations between poetry, education and social commitment of Cecilia Meireles, going through the ecopoetic vision in the reading of her work. Therefore, the aim is to highlight her pacifist ethics as both an educator and a poet, taking into comparative analysis the poems "Lamento do oficial por seu cavalo morto", from Mar absoluto (1945), and "Elegia a uma pequena borboleta", from Retrato natural (1949).

Keywords: Cecília Meireles. Ecopoetry. Social lyric. Pacifism.

Uma borboleta é um voo e uma cor.

Cecília Meireles

Em crônica publicada no Diário de Notícias em 16 de fevereiro de 1932, com o título "Asas de borboletas", Cecília Meireles menciona um fato "detestável" sobre a "indústria que vive do massacre das maravilhosas criaturinhas que enfeitam as florestas e os jardins do mundo" (2017, p. 61): o cardeal levará como presente ao Papa Pio XI um quadro feito de asas de borboletas.

A partir desse "pernicioso exemplo", ela tece tristes reflexões sobre como os católicos apresentarão o quadro às crianças - "obra-prima de

\footnotetext{
${ }^{1}$ Artigo recebido em 14 de agosto de 2019 e aceito para publicação em 27 de novembro de 2019.

2 Doutora em Literatura Comparada pela UFF, Professora Associada de Literatura Brasileira da UFRJ, Membro do GT da Anpoll A mulher na literatura e Coordenadora do Núcleo Interdisciplinar de Estudos das Mulheres na Literatura (NIELM/UFRJ). E-mail: aneliapietrani@letras.ufrj.br.
} 
bom gosto e de piedade" -, enquanto o esforço educacional pautado na dignidade humana e no acautelamento da infância da prática de todos os crimes se deparará com o desequilíbrio no processo de formação da mentalidade e do caráter das crianças. Ainda lamenta Cecília que essa contradição apareça nas escolas em algumas aulas de desenho e modelagem com animais e "outras vidas bonitas que não fugiram a tempo do alcance das mãos humanas" (2017, p. 61), assim como também esteja presente nos museus em exposições de bichinhos mortos e espetados como "uma das coisas mais horríveis que se podem mostrar à criança" (2017, p. 61). Essa delicada crônica sobre um fato tão pouco cristão nos abre à reflexão sobre o pensamento ecológico de Cecília Meireles em sua poesia de afeto e resistência.

Não podemos negar que a poesia lírica de Cecília tem sido muito mais lida por seu impulso para o absoluto, sua dimensão metafísica e mesmo espiritual, em que nuvem, mar, vento, água, rosa são motivos recorrentes que suscitam a reflexão sobre a existência - sempre fluida e efêmera - e a palavra não menos frágil e delicada, apesar de sua perenidade pelo canto. Tal veio poético teria conduzido a crítica, quase unanimemente, a uma leitura que, durante muito tempo, afastou a "pastora de nuvens" ${ }^{3}$ das coisas do mundo e da poesia política e social. A própria Cecília registrara em entrevista a Haroldo Maranhão, em 1949, que seu maior defeito seria "certa ausência do mundo" (1967, p. 87).

A modulação de sentido do pronome indefinido "certa" utilizado pela poeta nessa expressão acaba, no entanto, por suscitar o leitor a uma reflexão sobre o que, ao menos aparentemente, ela pretende negar. De que forma sua poesia dialoga com o mundo? Decerto que com a sutileza que lhe é peculiar, ou mesmo com sua palavra de delicadeza, como preferem muitos críticos. Mas, inegavelmente, o mundo está ali, com a presença altamente reveladora de sua consciência sobre o fazer poético.

"Tem sangue eterno a asa ritmada", diz a poeta em "Motivo", um de seus poemas mais famosos, que integra o livro Viagem (1939) ${ }^{4}$. Esse verso sinaliza que o ritmo da palavra em canção de sua poesia conjuga delicadeza e fragilidade, como dissemos, mas também remete à liberdade

${ }^{3}$ A persona lírica ceciliana assim se autodefine no poema "Destino", do livro Viagem (1939).

${ }^{4}$ As datas indicadas entre parênteses após os títulos dos livros referem-se ao ano de publicação da primeira edição da obra. 
da asa da imaginação. Ao mesmo tempo, indica que, fora da predominância exclusiva do etéreo e elevado, sua poesia tem sangue, o ritmo da energia vital e pulsante da palavra que se eterniza no pouco, no insignificante e no efêmero, revelados numa série de imagens poéticas recuperadas da natureza para a natureza poética de Cecília: a beleza sutil da rosa, a pequenez das formigas, a delicadeza das asas de borboleta, a retórica da simples pergunta "para quê?" da lagartixa, o ritmo rude e seco dos cascos de cavalos nas pedras.

A poesia de Cecília Meireles pode ser, assim, compreendida, simultaneamente, como pedra e sangue: a pedra da consciência humana em forma de reflexão transfigurada em palavra de delicadeza. Sua palavra poética torna-se, talvez, o sentido mesmo de poesia: a poesia que - como pedra - permanece na solidão contemplativa do eu; a poesia que - como sangue - flui em comunhão com o mundo, como tão bem refletiu Octavio Paz no ensaio "Poesia de solidão e poesia de comunhão", publicado originalmente em 1943:

\begin{abstract}
O que pretende o poeta quando expressa em poemas sua experiência? A poesia, disse Rimbaud, quer mudar a vida. Não quer embelezá-la, como pensam os estetas e os literatos, e sim torná-la mais justa, ou melhor, conforme sonham os moralistas. Através da palavra, através da expressão de sua experiência, busca tornar sagrado o mundo; sacramenta com a palavra a experiência dos homens e as relações entre o homem e o mundo, entre o homem e a mulher, entre o homem e a própria consciência. Não visa embelezar, santificar ou idealizar o que toca, mas torná-lo sagrado. Por essa razão, não é moral nem imoral, justa ou injusta, falsa ou verdadeira, bela ou feia. É, simplesmente, poesia de solidão ou de comunhão. Pois a poesia, que é um testemunho do êxtase, do amor feliz, também o é do desespero. E pode ser tanto uma súplica quanto uma blasfêmia (2017, p. 21-22).
\end{abstract}

"Uma borboleta é um voo e uma cor" (2017, p. 62), diz a educadora dos valores humanistas e a cronista da vida por um mundo habitável harmonicamente. Nessa frase, entre solidão e comunhão, fala também a palavra ecopoética de Cecília Meireles. 
Desde seus primeiros livros, o chamado da natureza ${ }^{5}$ se manifesta em sua poesia. Em Nunca mais... e poema dos poemas (1923), o "Poema da humildade" anuncia a relação semântica intrínseca entre chão, terra e interioridade das coisas e dos seres, que perpassará seus escritos. O húmus onde se harmonizam todos os elementos da natureza (pedra, raízes, árvores, sementes, animais, criaturas, sem qualquer hierarquização) é também o húmus do desejo da voz lírica de curvar-se até o chão, unir-se à natureza em palavra, a fim de falar do "milagre generoso/ de posteriores reproduções..." (2001, v.1, p. 80) e buscar a alma primitiva das coisas e dos seres, "mais abaixo do chão.../ muito abaixo do chão..." (2001, v.1, p. 82), já que tudo tem alma. Somente nessa descida ao mais humilde, e somente tomando a atitude humilde da descida, pode-se alcançar o ser da terra (convém recordar a etimologia comum a húmus, humilde e terra) e chegar ao chão, de onde torna a brotar outro ser, também pequeno, oculto, frágil, efêmero.

Essa reflexão reaparece no poema "Terra", do livro Viagem (1939), em que à ambiência natural se soma a criada pelo homem, com suas ambiguidades e seu infortúnio, enquanto a experiência poética é a descida abissal ao encontro do eu profundo, como podemos notar nos seguintes excertos do poema:

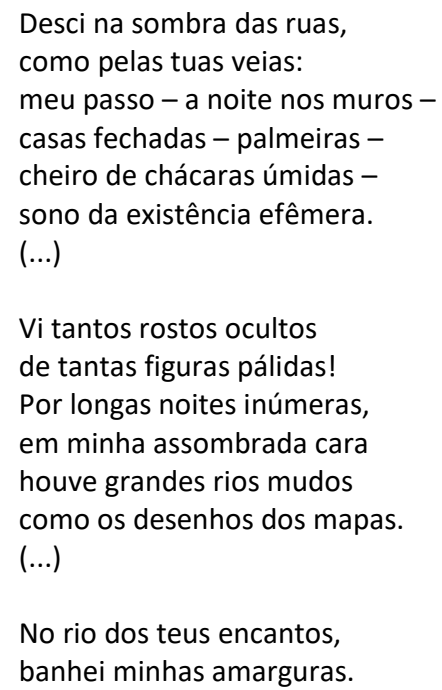

5 Importante estudo sobre o tema a partir da análise do poema "Madrugada no campo", de Cecília Meireles, encontra-se em: SADLIER, Darlene J. Imagery and theme in the poetry of Cecilia Meireles. Madrid: Studio Humanitatis, 1983, p. 85-99. 
Purifiquei meus enganos, minhas paixões, minhas dúvidas. Despi-me do meu desânimo fui como ninguém foi nunca. (...)

E esse foi o meu estudo para o ofício de ter alma; para entender os soluços, depois que a vida se cala. - Quando o que era muito é único e, por ser único, é tácito (2001, v.1, p. 253-254).

A constatação da harmonia da natureza e sua relação receptiva à presença humana assumem aspecto diferente nesse poema. Seu leitor é envolto por uma voz lírica que cria um mundo com uma natureza simples e acolhedora, quase impalpável de tão terna e delicada, ao mesmo tempo em que as palavras se conjugam em frases simples, melodiosas, encantadoras. No entanto, essa delicadeza e aparente simplicidade são sutilmente enganosas. A natureza deixa de ser - se é que foi em algum momento meramente referida por sua presença visível e passível de descrição, ultrapassando a ambiência retratada no poema e mesmo a contemplação da poeta. Para citarmos apenas alguns exemplos presentes nas estrofes acima, observemos que rios e ruas, noites e rostos, palmeiras e casas se complementam e formam grupos semânticos que denotam um mundo (de natureza e de cultura) marcado por conflitos e angústias, tanto do eu que fala no texto, como também das criaturas que nele vivem essa estranha harmonia a caminho da interioridade, exigido - como diz a poeta - por "esse ofício de ter alma". A natureza física e a natureza humana não se separam na poética ceciliana, antes confluem-se ecopoeticamente no espaço de sua poesia, porque ambas alimentam a reflexão sobre a problemática existencial com seus mistérios abissais, de que é ótimo exemplo o poema "Pequena flor", de Vaga música (1942):

Como pequena flor que recebeu uma chuva enorme e se esforça por sustentar o oscilante cristal das gotas na seda frágil, e preservar o perfume que aí dorme,

e vê passarem as leves borboletas livremente, e ouve cantarem os pássaros acordados sem angústia, e o sol claro do dia as claras estátuas beijando sente, 


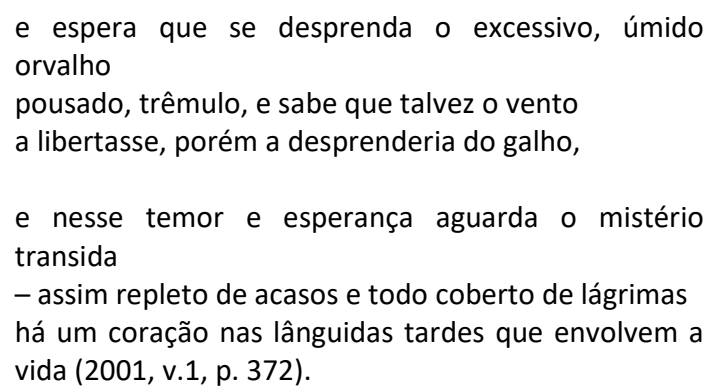

Presente em muitos outros poemas, essa reflexão se intensifica especialmente quando Cecília Meireles expressa sua consciência sobre o fazer poético, que significa para ela não apenas inventar e reinventar assuntos e técnicas, mas pensar o seu papel como poeta. Se se pode falar de uma natureza poética em relação ao mundo, ela existe em Cecília como cuidado do mundo, em que a amplamente discutida temática do mistério da existência se une à do mistério da criação poética, do compromisso social e da responsabilidade ética, todos ecopoeticamente atuantes na palavra. poema "Compromisso", do livro Mar absoluto (1945), é emblemático nesse sentido. Nele, três aspectos estão intimamente ligados:

a) ação poética como obrigação e trabalho árduo em prol da vida:

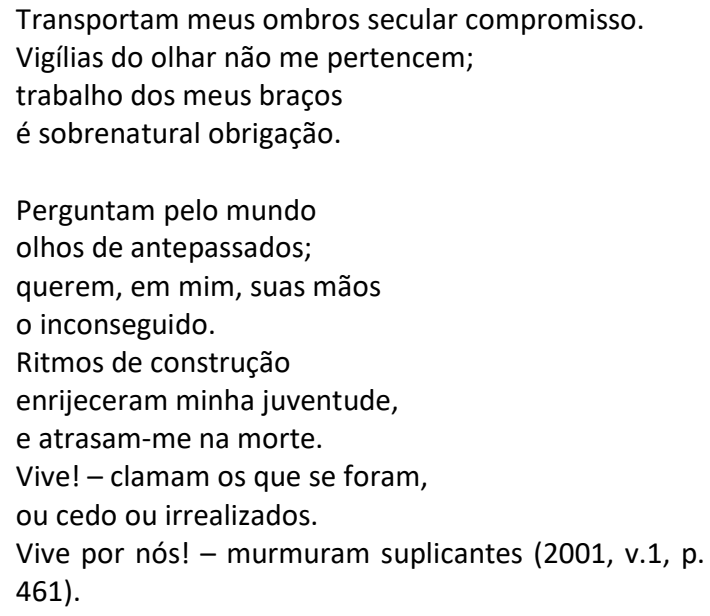

b) ação poética como atitude inspirada na harmonia da natureza, que não dissocia aspectos sociais e culturais, ou idades, épocas, espaços, gêneros; não hierarquiza coisas e seres, nem saberes místicos e entendimentos altos e baixos: 
Vivo por homens e mulheres

de outras idades, de outros lugares, com outras falas. Por infantes e velhinhos trêmulos.

Gente do mar e da terra,

suada, salgada, hirsuta.

Gente da névoa apenas murmurada.

É como se ali na parede

estivessem a rede e os remos,

o mapa,

e lá fora crescessem uva e trigo,

e à porta se chegasse uma ovelha, que me estivesse mirando em luar, e perguntando-se, também.

Esperai! Sossegai!

Esta sou eu - a inúmera.

que tem de ser pagã como as árvores

e, como um druida, mística.

Com a vocação do mar, e com seus símbolos.

Com o entendimento tácito,

instintivo,

das raízes, das nuvens,

dos bichos e dos arroios caminheiros (2001, v.1, p. 461-462)

(...)

c) ação poética como afeto, tanto no sentido de ser afetado(a) como no de afetar o outro; no sentido de responder pelo outro ou com o outro, praticamente como uma obrigação sacrificial e correspondência mística, exigidas pelo compromisso e cuidado com o outro e seu mundo:

Conduzo meu povo

e a ele me entrego.

E assim nos correspondemos.

Faro do planeta e do firmamento,

bússola enamorada da eternidade,

um sentimento lancinante de horizontes,

um poder de abraçar, de envolver

as coisas sofredoras,

e levá-las nos ombros, como os anhos e as cruzes.

E somos um bando sonâmbulo

passeando com felicidade

por lugares sem sol nem lua (2001, v.1, p. 462-463). 
A partir daí, outro flanco de reflexão se abre na ecopoesia de Cecília Meireles. É frequente em seus textos o desejo de acolhimento das "coisas sofredoras", que culmina no sentimento de habitar feliz o mundo, ainda que a voz poética reconheça suas angústias e seus infortúnios. "Acordar a criatura humana dessa espécie de sonambulismo em que tantos se deixam arrastar. Mostrar-lhes a vida em profundidade. Sem pretensão filosófica ou de salvação - mas por uma contemplação poética e afetuosa", disse Cecília na mesma entrevista de 1949, citada anteriormente. Cecília Meireles é a poeta do afeto e exige de nós uma resposta ética ao sofrimento do outro. Mas como reage o homem a essa exigência? O poema "Lamento do oficial por seu cavalo morto", também de Mar absoluto (1945), é uma possível resposta:

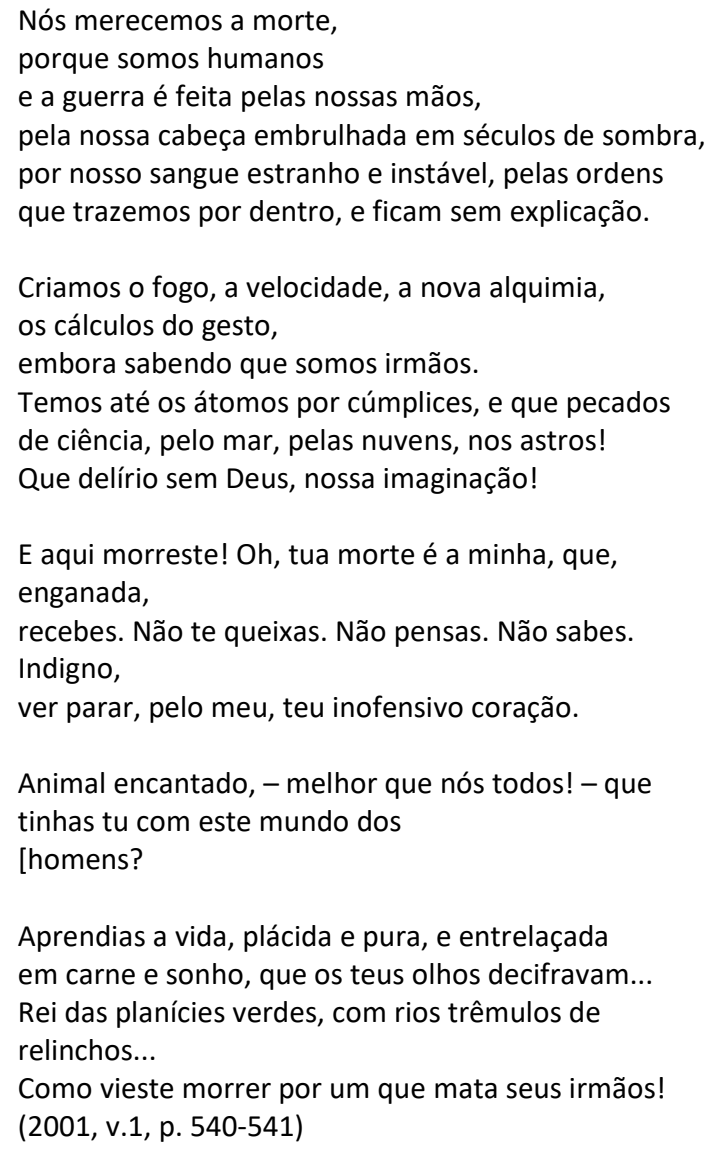

Em 1945, fim da Segunda Guerra Mundial, fim do Estado Novo no Brasil, Cecília Meireles publica o livro Mar absoluto. Nuvens, céus, campos, 
águas, mares, palavras, estes são os horizontes infinitos que atraem Cecília, por sua fluidez, imensidão, intangibilidade, mas também por suas correntes de fuga, perigo e violência: "Meu sangue entende-se com essas vozes poderosas./ A solidez da terra, monótona,/ parece-nos fraca ilusão./ Queremos a ilusão grande do mar,/ multiplicada em suas malhas de perigo" (2001, v.1, p. 449), ela diz no poema homônimo, que abre Mar absoluto. Nesse livro dos perigos do mar, muitos poemas conduzem nossa leitura à alusão direta à guerra, uma vez que tantos são os lamentos em forma de poesia: "Lamento da noiva do soldado", "Os presentes dos mortos", "Suave morta", "Balada do soldado Batista", "Lamento da mãe órfã", "Caronte", "Os mortos", "Lamento do oficial por seu cavalo morto", "Guerra" são alguns dos títulos que nos chamam a atenção por essa temática ${ }^{6}$.

$\mathrm{O}$ instante da segunda grande guerra no mundo, no entanto, não é o retrato único de Cecília. A guerra, em seus poemas, não tem tempo nem espaço definidos, é motivo para a reflexão sobre o estar no mundo, a relação do homem junto à natureza, a condição humana (e desumana). Nesse momento máximo de horror causado pelo homem, é significativa a pergunta da poeta no longo verso monóstico de "Lamento do oficial por seu cavalo morto" 7: "Animal encantado - melhor que nós todos! - que tinhas tu com este mundo dos homens?" Lançada ao leitor após os versos curtos e abruptos, que lembram, na forma do poema, os estampidos do tiro letal que atingiu o cavalo e a tomada de consciência - tiro a tiro, ponto a ponto - do oficial, a pergunta de Cecília faz também seu leitor perceber que o mundo movido pela razão instrumental e pela técnica calculada, um mundo sem afeto, sem Deus, sem humanidade, é um mundo que permite a guerra, a morte, a separação, a dor. Um mundo que inventa os instrumentos de violência é um mundo que implementa a mudança para um mundo mais violento ainda: "A prática da violência, como toda ação, muda o mundo, mas a mudança mais provável é para um mundo mais violento ainda" (2009, p. 101), diz Hannah Arendt em seus escritos sobre a violência.

\footnotetext{
${ }^{6}$ Sobre este tema nos poemas de Cecília Meireles, consultar: MOURA, Murilo Marcondes de. 0 mundo sitiado: a poesia brasileira e a segunda guerra mundial. São Paulo: Editora 34, 2016, p. 233-284.

7 Para uma longa e consistente análise deste poema, consultar: GOUVÊA, Leila Vilas Boas. Pensamento e "lirismo puro" na poesia de Cecília Meireles. São Paulo: Editora da Universidade de São Paulo, 2008, p. 193-209.
} 
"Nós merecemos a morte/ porque somos humanos", afirma Cecília pela voz do oficial. Mas o que dizer da pergunta não-pergunta "Como vieste morrer por um que mata seus irmãos!" - com que ela termina o poema, marcada com um inquietante ponto de exclamação? A bala que mata o cavalo é a mesma que atinge o oficial para a reflexão; é a que alveja a poeta e também seu leitor, explodindo na conscientização que exigirá a verdadeira humanização para o compromisso e cuidado com o mundo por meio da única ação possível: a não-violência. $E$ isso é motivo de aprendizado, como o do cavalo em sua vida passada, de placidez e pureza, cujo relincho se harmoniza com os rios trêmulos na perfeita aliteração do /r/ em consonância com a imagem poética criada. Isso é o que parece dizer a seu leitor a poeta e educadora. A palavra ecopoética de Cecília Meireles é sempre de esperança, ainda que - e por isso mesmo - consciente do modo de barbárie como vivemos e produzimos, daí o terrível "nós" inicial do poema: para Cecília, somos causa, mas igualmente somos solução para a barbárie.

Eis o que também nos parece evidente na história da borboleta agonizante de "Elegia a uma pequena borboleta", poema fundamental para a reflexão sobre a palavra ecopoética de Cecília Meireles, que integra o livro Retrato natural (1949):

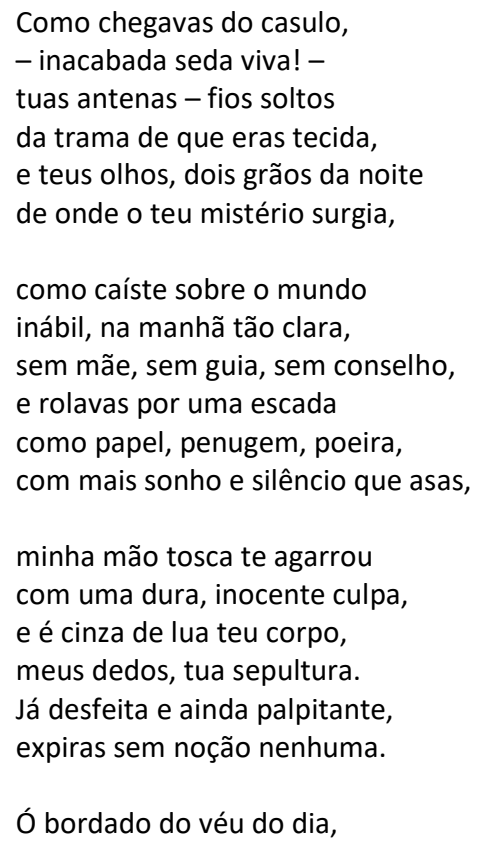

Ó bordado do véu do dia, 
transparente anêmona aérea! não leves meu rosto contigo: leva o pranto que te celebra, no olho precário em que te acabas, meu remorso ajoelhado leva!

Choro a tua forma violada, miraculosa, alva, divina, criatura de pólen, de aragem, diáfana pétala da vida! Choro ter pesado em teu corpo que no estame não pesaria.

Choro esta humana insuficiência:

- a confusão dos nossos olhos,

- o selvagem peso do gesto,

- cegueira - ignorância - remotos

instintos súbitos - violências que o sonho e a graça prostram mortos.

Pudesse a etéreos paraísos ascender teu leve fantasma, e meu coração penitente ser a rosa desabrochada para servir-te mel e aroma, por toda a eternidade escrava!

E as lágrimas que por ti choro fossem o orvalho desses campos, - os espelhos que refletissem - voo e silêncio - os teus encantos, com a ternura humilde e o remorso dos meus desacertos humanos! (2001, v.1, p. 608610)

A estrutura do poema lembra o adejar das asas das borboletas, que abrem e fecham, voam e flanam, como se os versos pares rimados e os ímpares livres reproduzissem, nessa cadência melodiosa dos versos octossílabos, o voo e o silêncio das borboletas nos campos, sobre as flores, entre as árvores. Tudo parece envolto numa atmosfera de simplicidade, até mesmo as palavras do texto, que foram escolhidas de um vocabulário de ternura e delicadeza, em perfeita consonância com a figura da borboleta, sua beleza, leveza e fragilidade. Essa aparente simplicidade também carrega a complexidade desse humilde ser. Mesmo pequeno e frágil, tem a função grandiosa e divina de fazer brotar novas vidas com seus quase invisíveis pés: "criatura de pólen, de aragem, / diáfana pétala da vida". 
O resultado desse movimento harmonioso entre o simples e o complexo é, no entanto, desconcertante para o eu poético, que também se depara com o intervalo entre "voo e silêncio", no caso, entre o último lampejo de vida da borboleta e sua morte por culpa do próprio eu que fala no texto. O desconcerto advém da mão tosca, que toca dura e violentamente o corpo do bichinho, ao chegar ao mundo inábil, e o leitor fica sem saber se é o mundo o inábil a lidar com a borboleta, ou mesmo ela, que cai sobre o mundo "sem mãe, sem guia, sem conselho", totalmente inábil, portanto. Sabe-se apenas que o universo dos homens, animais e vegetais seria sempre a casa da harmonia, se a mão humana fosse tão leve como a borboleta, que, pousada delicadamente sobre a flor, não pesa sobre o estame. Sem violência, o pequeno bichinho retira-lhe o pólen que vivificará. Ao contrário desse fenômeno natural de integração, a hierarquização entre dominadores e dominados existirá na natureza porque o homem, dotado de razão instrumental, pensa essa dominação. Entre borboleta e flor, entre os pequenos, a harmonia se faz plena, porque lá reina a natureza da solidariedade e união, sem qualquer competição, apesar de suas diferenças. A pequenez da intolerância é, de fato, humana.

Assim se traduzem em lamento os dois últimos poemas aqui referidos. Ambos lamentam a "insuficiência humana". Um, pela incapacidade de não se utilizar o que o próprio homem criou - a ciência, a tecnologia, a máquina - na preservação da morada dos homens, dos animais, das plantas, das águas, das pedras, para a vida integrada em calma e felicidade de todos os seres; mas, ao contrário disso, criou-se a arma e legitimou-se a violência com a guerra. Outro, pela intervenção negativa do homem na lida com os pequenos seres, desagregando o ecossistema com o triste dom de carregar "violências", assim mesmo, no plural, como a poeta destaca na "Elegia", assim como também utiliza o pronome plural "nossos", estendendo, desse modo, ao coletivo as violências provocadas. A "confusão" não é apenas de quem agarrou a borboleta com a mão tosca, mas de todos que são e veem insuficientemente: a confusão é "dos nossos olhos", o "peso do gesto" é selvagem, a cegueira e a ignorância são "remotos instintos súbitos" - articulados, contraditoriamente, por aquele que domina a natureza, em nome de uma falaz razão. A mesma razão the permite pôr-se contrariamente ao sentido de physis como totalidade do ser em natureza e opor-se hierarquicamente superior à pequena borboleta, 
morta "sem noção nenhuma", ou superior ao cavalo, também morto em situação muito semelhante ("Não te queixas. Não pensas. Não sabes").

Consciente do desejo desenfreado de domínio "racional" do homem sobre a natureza, e também do homem sobre o próprio homem, neste mundo tão pouco habitável pela harmonia dos contrários, a poesia de Cecília assume um compromisso. Ela deixa evidente o que o poeta pode fazer pela mão da poesia (a mão que destrói também é a que escreve): entoar sua voz humildemente, ajoelhando-se diante dos pequenos sofredores e celebrando-os com sua palavra de delicadeza, nem por isso com menos força e vigor. Em sua palavra ecopoética, o pequeno se faz grande. Por isso, a figura central desses dois poemas são os dois "pequenos" a quem a voz poética dirige seu canto elegíaco, seu sentimento e pensamento ecológicos de "ternura humilde" e "remorso de meus desacertos humanos". Os interlocutores dos dois poemas, o cavalo e a borboleta, ambos ausentes, porque mortos, estão presentes na mente do leitor, agora eternizados na memória do poema.

Se "uma borboleta é um voo e uma cor", como disse a cronista educadora, o homem é homem se suficientemente humano, bastando-se ao cuidado de si, do outro e da alma do mundo como morada da não-violência, pedagogia exemplarmente tematizada no seguinte fragmento de "Elegia sobre a morte de Gandhi", escrito pela poeta ecológica Cecília Meireles no exato dia da morte do pacifista indiano, em 30 de janeiro de 1948:

Deixou-te cair. Bruscamente. Bruscamente. Ainda restava dentro um sorvo de sangue. Ainda não tinha secado teu coração, fantasma heroico, pequena rosa desfolhada num lençol, entre palavras sacras.

O vento da tarde vem e vai da Índia ao Brasil, e não se cansa.

Acima de tudo, meus irmãos, a Não-Violência.

Mas todos estão com os seus revólveres fumegantes no fundo dos bolsos.

E tu eras, na verdade, o único sem revólveres, sem bolsos, sem mentira

- desarmado até as veias, livre da véspera e do dia seguinte.

Les hommes sont des brutes, madame.

O vento leva a tua vida toda, e a melhor parte da minha. 
Sem bandeiras. Sem uniformes. Só alma, no meio de um mundo desmoronado.

Estão prosternadas as mulheres da índia, como trouxas de soluços (2001, v. 2, p. 1609).

A palavra ecopoética de Cecília existe em prol da educação e integração pela paz, Em sua forma muito própria, "entre as mil rosas de cinza de teus velhos ossos, Mahatma" (2001, v. 2, p. 1611), Cecília Meireles é voz que prenuncia, na literatura brasileira, o Flower Power.

\section{Referências}

ARENDT, H. Sobre a violência. Trad. André Duarte. Rio de Janeiro: Civilização Brasileira, 2009.

GOUVÊA, L. V. B. Pensamento e "lirismo puro" na poesia de Cecília Meireles. São Paulo: Editora da Universidade de São Paulo, 2008.

MEIRELES, C. Asas de borboletas. In: . Crônicas de educação. 2ạ. ed. São Paulo: Global, 2017, v. 4, p. 61-62. Notícia biográfica. In: Obra poética. 2ạ. ed. Rio de Janeiro: Aguilar, 1967, p. 75-89.

Poesia completa: edição do centenário. Organização de Antonio Carlos Secchin. Rio de Janeiro: Nova Fronteira, 2001, 2 v.

MOURA, M. M. O mundo sitiado: a poesia brasileira e a segunda guerra mundial. São Paulo: Editora 34, 2016.

PAZ, O. Poesia de solidão e poesia de comunhão. In: A busca do presente e outros ensaios. Trad. Eduardo Jardim. Rio de Janeiro: Bazar do Tempo, 2017, p. 11-37.

SADLIER, D. J. Imagery and theme in the poetry of Cecília Meireles. Madrid: Studio Humanitatis, 1983. 